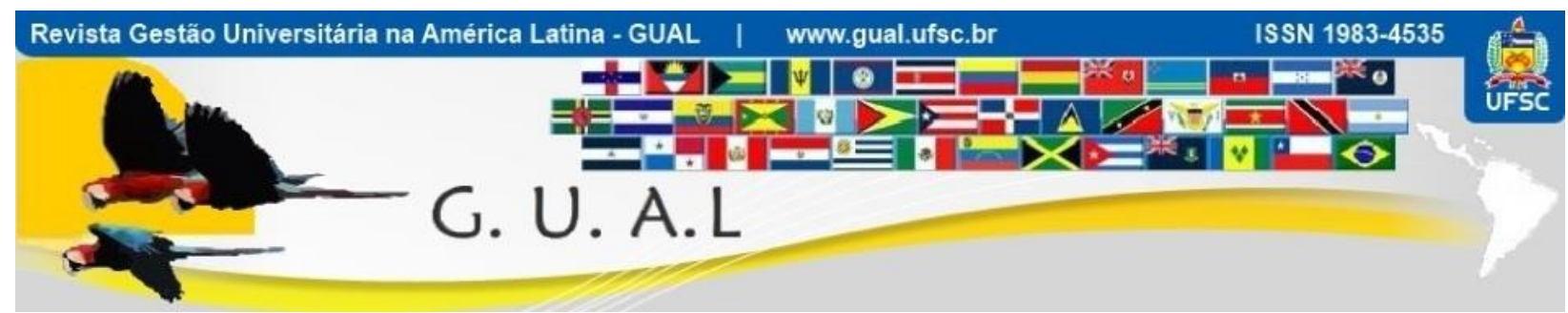

DOI: http://dx.doi.org/10.5007/1983-4535.2015v8n2p134

\title{
COMPETÊNCIAS PARA A GESTÃO: EXPECTATIVA DE ALUNOS DO CURSO DE ADMINISTRAÇÃO DA UEMA, DE GESTORES E SEUS PARES NA VALE S.A. EM SÃO LUIIS - MA
}

\section{MANAGEMENT SKILLS: THE EXPECTATION OF BUSINESS STUDENTS OF UEMA, THEIR MANAGERS AND PEERS IN VALE SA IN SAO LUIS - MA}

José Rômulo Travassos da Silva, Doutorando Universidade Estadual do Maranhão - UEMA romulo.travassos.silva@gmail.com

Valderez Ferreira Fraga, Doutora Fundação Getulio Vargas - Escola Brasileira de Administração Pública e de Empresas valorerh@centroin.com.br

Deborah Moraes Zouain, Doutora Fundação Getulio Vargas - Escola Brasileira de Administração Pública e de Empresas deborah@fgv.br

Gustavo de Oliveira Almeida, Doutor Fundação Getulio Vargas - Escola Brasileira de Administração Pública e de Empresas goalmeida@gmail.com

Recebido em 10/maio/2013

Aprovado em 26/abril/2014

Sistema de Avaliação: Double Blind Review

Esta obra está sob uma Licença Creative Commons Atribuição-Uso. 


\title{
COMPETÊNCIAS PARA A GESTÃO: EXPECTATIVA DE ALUNOS DO CURSO DE ADMINISTRAÇÃO \\ DA UEMA, DE GESTORES E SEUS PARES NA VALE S.A. EM SÃO LUÍS - MA \\ DOI: http://dx.doi.org/10.5007/1983-4535.2015v8n2p134
}

\section{RESUMO}

Avanços tecnológicos somados à Globalização têm contribuído para competitividade/ complexidade organizacional. A sobrevivência das empresas, nesse cenário, relaciona-se à criação e ao desenvolvimento de recursos e meios que lhes confiram competitividade. Daí a competência dos indivíduos tornar-se foco deste estudo, cujo objetivo central enfoca congruência ou não entre as competências adquiridas pelos alunos do Curso de Administração do Centro de Ciências Sociais da Universidade Estadual do Maranhão - tanto segundo os sujeitos escolhidos no espaço acadêmico do Administrador - alunos e gestores - e as competências exigidas pelos gestores das empresas de São Luís - MA, como a VALE. A metodologia articulou métodos qualitativos e o referencial teórico em competências recorreu a vários autores. Os resultados mostraram elementos conceituais mais citados em competência, conhecimentos, habilidades, atitudes e capacidades e a preferência dos sujeitos pela formulação de Queiroz (2008). O conhecimento foi a base da congruência encontrada entre alunos e gestores da UEMA e da VALE. O destaque da empresa à capacidade analítica na seleção de candidatos reporta à insatisfação dos alunos aos métodos de ensino. O estágio merece diálogo entre as duas organizações. Futuros estudos poderão aprofundar questões como satisfação dos alunos, ensino na UEMA, desempenho acadêmico e profissional.

Palavras chaves: Competência. Curso de Administração. Organização. Congruência.

\begin{abstract}
Technological advances summed up with globalization have contributed for organizational competitiveness/complexity. The survival of business in this scenario is related to the creation and development of resources and assets which give them competitiveness. Individuals competence has become the focus of this study whose central objective focus on congruence or otherwise between the skills acquired by students of the Center for Social Sciences at the State University of Maranhão - according to the subjects chosen in the Administrator's academic training space, students and administrators, and skills required by private sector managers' in Sao Luis - MA, in the VALE company as well. The methodology has articulated qualitative research methods. The theoretical framework drew on expertise of several authors' design. The results showed as the most cited competence elements, knowledge, skills, attitudes, capacity and the preference on Queiroz's competence version (2008) was the most accepted. Knowledge was the congruence base found among students and managers at UEMA and Vale. The enterprise distinction on analytical capacity for candidates' selection, reports to student's dissatisfaction about teaching methods. Trainees' step deserves better dialogue between both organizations. Future studies can deepen questions as students' satisfaction, teaching at UEMA, academic and work performance.
\end{abstract}

Key words: Competence. Administration Program. Organization. Congruence. 


\section{INTRODUÇÃO}

Com o advento da globalização, o mercado de trabalho tornou-se cada vez mais exigente no que se refere às competências, impactando o conteúdo do curriculum vitae de candidatos e empregados para assumirem cargos já existentes e os novos, nas organizações. Em geral o desafio dos processos seletivos é uma constante, passando a exigir maior número de características específicas e ou até inesperadas de seus colaboradores, muitos dos quais ainda não aprenderam a reconhecê-las que dirá a internalizá-las enquanto competências que os permita o exercício de suas funções e atribuições, de acordo com as expectativas organizacionais.

Nesse contexto, parecem não estar bem estabelecida a relação entre Escolas, Universidades e Empresas. A aprendizagem tem um foco específico nos conteúdos intelectuais, levando o aluno a aprender em maior proporção as teorias e técnicas, esquecendo, assim, o ensino e o desenvolvimento comportamental e psicossocial dos alunos, suas atitudes e valores. A expectativa de que boa parte dessa formação comportamental e psicossocial deve vir, para o indivíduo, a partir do grupo primário, a família, tem poucas chances de se realizar, muito particularmente em países ainda em desenvolvimento, onde o acesso à educação dos pais e a baixa renda são uma característica marcante da sociedade. Logo, até que ponto a família caminha paralelamente com a escola, contribuindo na construção dessas características comportamentais e psicológicas do indivíduo, é uma resposta relativamente fácil de inferir e nada animadora.

Percebem-se, no contexto social, grandes discussões quanto às responsabilidades da família e da escola na formação educacional do aluno. Enquanto a escola se esforça nessa missão, apesar de condições frequentemente frágeis, acontece de a família ter pouca participação, atribuindo esse papel apenas aos professores. Certamente, as razões não se esgotam no exposto acima, porém o peso das condições sociais adversas costuma ser de conhecimento público.

A congruência entre a escola e a família, no sentido do esperado da formação educacional do aluno, diverge em maior proporção no papel que deverá ser exercido por cada instituição, mais fortemente quanto atitudes e valores e o aluno, por sua vez, ainda em fase de formação da sua personalidade, acaba por internalizar comportamentos e atitudes em situações adversas. 
A influência e a congruência na formação educacional, portanto, parece estar vinculada aos fatos que são vividos e incorporados pelo indivíduo na convivência na escola, na família e na sociedade em que o mesmo se encontra inserido.

Embora os valores e crenças de cada grupo social sejam diferentes, poderão existir mecanismos de congruência, quando se acredita na capacidade de mudanças que possibilite uma interação dessas características, promovendo-se uma articulação social capaz de adquirir e disseminar o que a sociedade e o mercado de trabalho esperam dos indivíduos, em termos da sua formação profissional.

Se, por um lado, o regime educacional do País cria métodos para avaliar a intelectualidade do estudante, por outro lado, a formação psicossocial fica em desvantagem. Embora essas duas instâncias tenham importâncias similares, a primeira pode requerer um tempo mais curto e delimitado, enquanto a segunda, requer médio e longo prazo, sem limites para aprender. A aprendizagem psicossocial é uma aprendizagem contínua, onde o ambiente vai pesar também nas escolhas até os conteúdos a serem aprendidos.

Este artigo tem por objetivo levantar a congruência ou não, entre as competências adquiridas pelos alunos do Curso de Administração do Centro de Ciências Sociais Aplicadas (CCSA) da Universidade Estadual do Maranhão, segundo os sujeitos escolhidos no espaço acadêmico definido para a formação do Administrador e as competências exigidas pelos gestores da VALE em São Luís-MA, segundo os sujeitos escolhidos nesse espaço empresarial delimitado.

Neste ponto, vale lembrar que a questão da relação social cabe, também, no caso das pessoas e das suas organizações. Reportando-se a Max Weber (2009), Kirschbaum e Iwai (2011), consideram ação social quando os indivíduos levam em conta a ação dos outros, tomando decisões estratégicas nesse sentido.

\section{GESTÃO DE PESSOAS NO CONTEXTO DE UMA NOVA PROPOSTA}

A gestão de pessoas nas organizações tem passado por profundas mudanças em todo o mundo, motivadas pela inadequação ou até mesmo pela ineficiência dos modelos tradicionais em relação às demandas e expectativas das organizações empresariais e das pessoas no mundo globalizado e tecnologicamente avançado.

Os modelos de gestão envolvem um conjunto de pressupostos, práticas e instrumentos. Os modelos tradicionais são originários dos movimentos de administração científica, na busca 
da pessoa certa para o lugar certo (TAYLOR, 1982) e estão respaldados no controle como referencial para enfrentar a relação entre as pessoas e a organização (FLEURY; FISCHER, 1992).

As transformações na forma de gerir pessoas ocorreram ao longo dos últimos vinte anos. Dentre as principais, Dutra et al. (2001, p. 25) citam as seguintes:
a) Alteração no perfil das pessoas exigido pelas empresas;
b) Deslocamento do foco da gestão de pessoas por meio do controle para o foco por meio do desenvolvimento;
c) Maior participação das pessoas no sucesso do negócio ou da empresa.

Os conceitos de entrega, complexidade e espaço ocupacional podem subsidiar a compreensão da realidade organizacional com maior clareza, quando se analisam as políticas e práticas de gestão de pessoas nas organizações e se buscam ferramentas de gestão mais eficientes e adequadas para essa análise.

Esses conceitos, traduzidos em ferramentas de gestão de pessoas, podem receber tradução de diversas formas. Verifica-se, atualmente, uma evolução relevante nas ferramentas de gestão partindo desses conceitos, no entanto, ainda existe um extenso caminho a ser explorado e mesmo a concepção do que seria competência emerge com variações significativas entre os autores. Provavelmente por essa razão Freitas e Brandão (2006, p.98) destacaram o conceito que apareceu com aceitação mais ampla tanto na academia quanto no ambiente empresarial, a saber: “competências representam combinações sinérgicas de conhecimentos, habilidades e atitudes, expressas pelo desempenho profissional dentro de determinado contexto organizacional” (DURAND, 2000).

Retornando à aplicação dos conceitos mencionados anteriormente, o principal desafio diz respeito à construção de uma escala que possibilite mensurar o nível da complexidade da "entrega" pelas pessoas e a citada entrega pelas pessoas representa o que cada uma delas pode contribuir para a construção e desenvolvimento da organização, ao mesmo tempo, possibilitando a gratificação pessoal dessas pessoas. Por entrega, entende-se, pois a aplicação prática das competências, gerando valor para a organização. Considerar a capacidade de entrega das pessoas é uma maneira de avaliá-las, orientá-las, desenvolvê-las, recompensá-las (DUTRA et al., 2001).

Essa entrega pelas pessoas representa, simultaneamente, o que cada uma delas pode contribuir para a construção e desenvolvimento da organização, E a gratificação pessoal desses atores. Por entrega, entende-se a aplicação prática das competências, gerando valor 
para a organização. Considerar a capacidade de entrega das pessoas é a maneira considerada adequada de avaliá-las, orientá-las, desenvolvê-las e recompensá-las (DUTRA et al., 2001).)

A inclusão da questão da complexidade na construção de um modelo de gestão voltado para o desenvolvimento, favorece os desdobramentos, a saber: análise das singularidades das pessoas a partir de suas ações e ou omissões, em termos de eficiências individuais; análise da efetividade social das ações de desenvolvimento e adequação das mesmas ao desenvolvimento pretendido. (DUTRA et al., 2001).

A análise dessa questão está dividida em duas partes; $1^{a}$ ) a importância e uso de uma escala de complexidade; e $2^{a}$ ) as formas de administrar essa escala.

A escala para medir a complexidade das entregas pelas pessoas pode ser aplicada nas seguintes situações: (DUTRA, 2001)

a) Mensurar o desenvolvimento - ao se medir o nível de complexidade das atribuições e das responsabilidades de uma pessoa em um período e, após algum tempo, mensurá-lo novamente é possível evidenciar se houve ou não desenvolvimento do indivíduo avaliado e, assim, constatar o grau desse desenvolvimento;

b) Avaliar a eficiência de ações de desenvolvimento - essa avaliação ocorre quando se mede o nível de complexidade da atuação de uma pessoa antes e após a realização de uma ação de desenvolvimento, acrescentando-se o tempo necessário à transformação da ação;

c) Estimular o auto-desenvolvimento - ao medir seu próprio desenvolvimento, as pessoas procuram o aprimoramento profissional;

d) Valorar a escala salarial - todo indivíduo, ao assumir maior nível de complexidade de atribuições e responsabilidades, passa a valer mais. Então, pode-se construir uma escala salarial vinculada á escala de complexidade, estabelecendo-se relação entre o desenvolvimento e a remuneração na perspectiva de utilizar esta ultima como motivação para o desenvolvimento;

e) Dimensionar o quadro - com base na escala de complexidade por ser possível estabelecer quantas pessoas serão necessária em cada processo e níveis de complexidade. A maior proximidade da empresa de um quadro ótimo significa maior otimização da folha de pagamento de pessoal; 
f) Otimizar investimentos em desenvolvimento - tomando-se por base o dimensionamento do quadro, a escala de complexidade e (n)a avaliação do posicionamento de cada pessoa nessa escala. Assim, a empresa passa a dispor de uma visão clara das carências e excessos em cada nível de complexidade, ou seja, como e onde concentrar esforços e reforços para obter melhor desenvolvimento;

g) Avaliar desempenho - trata-se de uma das questões mais complexas na gestão de pessoas. Pode-se definir desempenho como o conjunto de entregas e de resultados do trabalho de uma pessoa para uma organização ou negócio. Essa avaliação divide-se em três dimensões interrelacionadas. A primeira refere-se ao desenvolvimento, a segunda diz respeito ao esforço e a terceira ao comportamento. As proposições de avaliação de desempenho tornam-se equivocadas quando as três dimensões destacadas a seguir transformam-se em uma única ferramenta: $1^{\mathrm{a}}$ ) o nível de desenvolvimento de uma pessoa determina minha expectativa de desempenho sobre a mesma; $2^{a}$ ) o esforço de uma difere do seu desenvolvimento por causa da qualidade de sua agregação para a empresa. Neste aspecto as empresas preocupam-se mais com o desenvolvimento do indivíduo, visto que seu esforço não garante uma continuidade dos padrões esperados pela Organização. $3^{a}$ ) o comportamento pode afetar ou não o desenvolvimento e o esforço da pessoa, afetando certamente o ambiente organizacional e $o$ desenvolvimento, bem como o esforço dos outros indivíduos. Desta forma o comportamento deve ser avaliado separadamente em virtude de sua subjetividade. Para tanto sugere-se a avaliação de desempenho $360^{\circ}$ que minimiza a subjetividade bem como apresenta ao indivíduo a percepção pública à seu respeito.

Os níveis de complexidade podem ser mensurados levando-se em consideração o intervalo de tempo entre a tomada de decisão e a possibilidade de avaliação dos resultados advindos da mesma. Dependendo da extensão do tempo, elevar-se-á, também, o nível de abstração indispensável para que a decisão tomada apresente-se correta e efetivamente (JAQUES, 1988).

De acordo com Jaques (1988), é possível identificar sete níveis de complexidade nas organizações, aos quais denominou de work levels (níveis de trabalho) e os relacionou à dimensão temporal segundo as categorias a seguir: 


\begin{tabular}{|l|l|}
\hline 0 a 3 & $\begin{array}{l}\text { Trabalhadores de chão-de-fábrica e trabalhadores } \\
\text { qualificados, incluindo os supervisores. }\end{array}$ \\
\hline 1 a 12 & $\begin{array}{l}\text { Primeiro nivel gerencial e gerentes que respondem por } \\
\text { operacões ou processos simples. }\end{array}$ \\
\hline $\begin{array}{l}\text { Gerentes de nivel médio e táticos que respondem por um } \\
\text { conjunto de processos. }\end{array}$ & $\begin{array}{l}\text { Gerentes seniores que respondem por decisões estratégicas, } \\
\text { geralmente vosicionados como diretores. }\end{array}$ \\
\hline 10 a 20 & $\begin{array}{l}\text { Nivel tipico de presidentes de empresas } \\
\text { Profissionais responsáveis por um grupo de empresas ou } \\
\text { mesmo organizacões de atuacão transnacional. }\end{array}$ \\
\hline Mais de 20 & $\begin{array}{l}\text { Esta é uma caracteristica do CEO (chief executive officer) } \\
\text { de empresas de grande porte que atuam em vários países e }\end{array}$ \\
\hline
\end{tabular}

Fonte: Adaptado de Jaques, 1988.

O autor desses níveis, expressa, nessa classificação, os níveis de complexidade das organizações com base nos graus das tarefas de trabalho.

Billis e Rowbottom (1987) desenvolveram um conjunto maior de referenciais para mensurar os níveis de complexidade. Esses dois estudiosos percebiam que a utilização do intervalo de tempo como única forma de medida é de difícil aceitação, apesar de que, muitas vezes, não se leva em conta as características de modelos organizacionais específicos ou a natureza dos problemas que devem ser gerenciados.

Ambos os autores tentaram associar a cada nível definido por Jaques (1988) a complexidade, partindo do processo de tomada de decisão, vinculando-os à maturidade do profissional.

A associação do conceito de complexidade ao de competência decorreu dos trabalhos realizados em empresas nacionais e transnacionais, voltados para a estruturação de sistemas de gestão de pessoas. A competência, para fins desses projetos, ao definir o que se espera do profissional no tocante ao resultado do seu trabalho ou, ainda, segundo designam 
determinadas organizações, aquilo que ele entrega para a empresa ou negócio. A expectativa dessa entrega se diversifica de acordo com os níveis de complexidade. A posição na estrutura e a maturidade profissional determinam o nível de expectativa dos profissionais que são atores em diferentes níveis hierárquicos no trabalho.

\begin{abstract}
Ao associar os conceitos de complexidade às competências, é possível definir, para cada competência, diferentes níveis de complexidade de entrega. Tais níveis não precisam estar diretamente associados aos estratos sugeridos por Jaques, mas é fundamental que possuam uma relação consistente com as características da empresa e com os elementos relevantes do mercado em que ela está inserida. Essa relação atende melhor às especificidades de cada organização e garante maior flexibilidade, gerando estratos alinhados às características e à cultura de cada uma das organizações (DUTRA et al., 2001, p.38).
\end{abstract}

Para exemplificar, Dutra et al. (2001) demonstram três competências previstas para a carreira gerencial e, para cada uma delas, cinco níveis de complexidade de entrega esperados/pretendidos: orientação estratégica, organização e gestão de processos de mudança.

A orientação estratégica envolve o comprometimento a valores, missão e visão da empresa. Objetiva explicitar e aumentar a consciência da importância dessas competências àqueles que interagem. Com base na estratégia organizacional estabelecem-se planos de ação concretos, fundado na análise de tendências do ambiente.

A vivência da gestão da Universidade possibilitou observar que a orientação estratégica estaria voltada para que seus auxiliares/colaboradores pautassem sua entrega na efetivação dos valores, missão e visão dessa instituição, o que requer empenho de todos e consciência da importância dessa competência para a organização institucional. Contudo, para o alcance dessa expectativa, faz-se necessário, ainda, que a Universidade defina planos que atendam às necessidades daqueles que interagem na estrutura organizacional, como também, acompanhe as tendências do meio ambiente.

Zarifian (2001) destaca três mutações principais que ocorreram no mundo do trabalho, as quais justificam a emergência do modelo de competências para a gestão das organizações, sendo:

a) A noção de incidente: aquilo que ocorre de forma imprevista, não programada, vindo a perturbar o desenrolar normal do sistema de produção, ultrapassando a capacidade rotineira de assegurar sua auto-regulação. Isso implica que a competência não pode estar contida nas predefinições da tarefa, fazendo com que as pessoas precisem estar sempre mobilizando recursos para resolver novas situações. 
b) A noção de comunicação: que implica a necessidade de as pessoas compreenderem o outro e a si mesmas para partilharem também objetivos e normas organizacionais.

c) A noção de serviços: a compreensão de atender a um cliente externo ou interno à organização precisa ser central e presente em todas as atividades.

Nos dias atuais, o trabalho não se caracteriza como um conjunto de tarefas associadas à descrição do cargo, mas se torna a extensão direta da competência que o indivíduo mobiliza mediante uma situação profissional que, a cada dia sofre mutações e se apresenta mais complexa. É preciso estar alerta, pois, apesar de parecer estranho, tal complexidade, em lugar de enriquecer as atividades, pode propiciar um cotidiano rotineiro.

$\mathrm{O}$ desenvolvimento das organizações, baseado em consideração quanto às competências, pode ter, como resultados, melhores oportunidades de pesquisa e implementação de sistemas de administração de recursos humanos eficazes (DAVIS, 1997). Segundo Davis (1997, p. 42), “a maior consequência dessa evolução organizacional é seu impacto sobre a maneira de se fazer o trabalho e a maneira como essas organizações tratam dos relacionamentos entre os empregados e o trabalho". Essa reflexão do autor estimula a expectativa do emprego de competências na gestão da universidade.

No Brasil, o assunto é debatido no âmbito acadêmico, motivando gestores e pesquisadores, como ocorreu com esta decisão pelo tema em análise, porém, adentra as empresas de maneira mais pragmática. Percebeu-se, contudo que, paulatinamente, novos conceitos e um novo vocabulário foram introduzidos no dia a dia empresarial, na realidade brasileira aqui enfocada e, assim, preparam-se para a utilização do conceito de competência na dinâmica da gestão organizacional.

\section{METODOLOGIA}

$\mathrm{O}$ tipo de pesquisa utilizada neste trabalho não opta pela "dicotomia qualitativa $\mathrm{x}$ quantitativa, considerada "uma falsa dicotomia" (VIEIRA, 2004, p.13), procurando empregar cada método no momento em que se mostrar adequado. A pesquisa qualitativa é empregada visto que essa linha metodológica:

[...] trabalha na perspectiva de identificação e análise de significados, crenças, comportamento, valores e atitudes que convergem a um universo mais amplo das 
relações interpessoais e dos processos de aprendizagem que não podem ser minimizados a simples operacionalizações de variáveis (MINAYO, 1994, p. 10).

O universo da pesquisa está delimitado pela Universidade Estadual do Maranhão e a empresa VALE, na cidade de São Luís, selecionada pelo critério de visibilidade no mercado e, também, acessibilidade.

A amostra da pesquisa contemplou alunos do $8^{\circ}$ e $10^{\circ}$ períodos do Curso de Administração do Centro de Ciências Sociais Aplicadas da UEMA, no segundo período de 2009, uma vez que esses períodos integram os alunos concluintes da graduação em Administração, dos turnos vespertino e noturno, visto que os mesmos participam de uma mesma grade curricular com os mesmos docentes. Contemplou, ainda, gestores, em especial de RH, da VALE, unidade atuante na cidade de São Luís-MA.

Os sujeitos da pesquisa, no âmbito da dimensão espacial definido para a UEMA, situaram-se nos concluintes do Curso de Administração dos turnos vespertino e noturno do CCSA, escolhidos aleatoriamente, com base na relação dos alunos concludentes, da qual foram selecionados seis alunos de cada turno.

A pesquisa bibliográfica fundamentou-se em matérias publicadas em livros, revistas, periódicos, dissertações e teses relacionados com o problema objeto deste estudo.

A pesquisa documental incluiu documentos que relatam a vida da Universidade e do Curso de Administração, bem como do Projeto Pedagógico do referido Curso.

As respostas para os questionários receberam um tratamento estatístico básico - em coerência com a previsão do emprego do método quantitativo; isso se dá por meio de uma escala gráfica, que possibilita a enumeração das respostas por categoria e ordenação das mesmas por nível de importância para o respondente.

No âmbito qualitativo, a busca para procurar iluminar o sentido das atuais relações e possibilidades a partir de um diálogo entre as singularidades das organizações estudadas pode sugerir um arejamento no pensar e no agir em benefício mútuo e social, envolvendo a todos.

\section{APRESENTAÇÃO E ANÁLISE DE DADOS}

Os resultados do estudo foram obtidos por meio da interpretação dos dados compilados e analisados com base no referencial teórico, visando dar resposta às questões definidas previamente.

A análise dos dados obtida na pesquisa, tanto bibliográfica quanto de campo, foi respaldada pelo referencial teórico exposto anteriormente, através do qual foi possível 
identificar as competências comuns apontadas pelos teóricos e pelas organizações, universo do estudo.

Os resultados foram analisados à medida que os depoimentos dos sujeitos foram sendo obtidos e organizados, na seguinte ordem: os alunos, os gestores da VALE e os gestores da UEMA.

Dentre as definições de competência apresentadas por vários teóricos, $50 \%$ dos alunos selecionaram a de Queiroz (2008) que, inclusive aponta os elementos indicados em suas próprias definições. "Competência é o conjunto de conhecimentos, habilidades e atitudes correlacionadas que, em ação, agregam valor ao indivíduo e à organização, ao que denominamos de "entrega" (QUEIROZ, 2008, p.35).

As competências indicadas pelos alunos, como adquiridas durante o Curso de Administração da UEMA e que os teria preparado para enfrentar o mercado de trabalho, estão relacionadas aos fatores a seguir: tomada de decisão, trabalho em equipe, liderança e conhecimento.

De acordo com os alunos, as competências são desenvolvidas ao longo da vida do ser humano, nos aspectos intelectual e emocional, pois o ser humano possui capacidade para incorporar novas habilidades, cuja evolução depende da necessidade e da influência do meio no qual está inserido. Por sua vez, dentre os aspectos que, segundo os próprios alunos, a UEMA pode contribuir para o desenvolvimento de suas competências, ressaltaram fatores como aplicações práticas, intensificar a participação dos alunos em experiências profissionais e no estágio, esclarecer as competências a serem desenvolvidas pelo Curso, capacidade de liderança, relacionar teoria e prática, capacitação de professores, dentre outros de menor recorrência.

A maioria dos alunos ressaltou que as disciplinas oferecidas no Curso proporcionaram aprendizagem profissional, além do conhecimento acadêmico, no entanto, 40\% salientaram que não contribuem para o referido aprendizado.

A congruência entre as competências desenvolvidas durante o Curso e as exigidas pela demanda de mercado, para $60 \%$ dos alunos é evidente, portanto, é um fato a considerar na gestão do conhecimento e na avaliação da universidade.

Os alunos, em maioria, vinculam-se ao desenvolvimento do aprendizado intelectual e não emocional o que foi justificado principalmente, porque, o Curso possibilitou maior 
desenvolvimento das questões teóricas. As mudanças indicadas para o Curso foram mais relacionadas às atividades extraclasse e à metodologia empregada pelos professores.

Quanto ao conceito de competência, o apresentado por Queiroz (2008), foi escolhido por $66,7 \%$ dos gestores, como o mais próximo das expectativas dos mesmos. Tal definição apresenta correspondência dos elementos chaves dos conceitos destacados pelos gestores.

As principais competências exigidas pela Organização de trabalho para a admissão do administrador e indicadas por esses gestores têm como foco os seguintes fatores: resultados sustentáveis, capacidade analítica e habilidades relacionais.

A prática entre a UEMA e a VALE, de modo a favorecer a congruência das competências adquiridas pelos alunos, com relação àquelas exigidas pela Organização ou mercado de trabalho existe, em parte, conforme a maioria dos gestores entrevistados e apenas para uma minoria, não acontece.

Na concepção de todos os sujeitos da pesquisa, o diálogo entre UEMA e VALE poderia ser melhor: mais frequente, mais próximo, mais aberto.

Passando-se à análise dos dados referentes aos gestores da UEMA, estes definiram competência destacando os seguintes elementos: conjunto de saberes, habilidades e atitudes correlacionadas, que em ação agregam valor ao indivíduo e à organização, ao que denominamos de 'entrega'. A definição de competência escolhida entre os autores apresentados foi a de Queiroz (2008), com indicação de 50\% dos sujeitos.

Na perspectiva do autor, a competência é uma manifestação que se desenvolve “em conjunto", proporcionando ao sujeito o desenvolvimento simultâneo do conhecimento, das habilidades e das atitudes. Essa tríade, por sua vez, relaciona-se ao saber, saber fazer, querer fazer e fazer. Esta última etapa diz respeito à entrega do sujeito na execução efetiva de uma determinada atividade.

Como competências fundamentais para a UEMA, na formação dos administradores, no foco do mercado de trabalho, esses gestores voltaram-se para os elementos: conhecimento, trabalho em equipe e liderança.

Quanto à congruência entre competências adquiridas pelos alunos e as exigidas pelas empresas, a maioria dos gestores $(66,7 \%)$ indicaram que não acontece, isto é, os alunos não desenvolveram no decorrer do curso as competências necessárias para a gestão organizacional esperadas pela empresa. Isto pode indicar a necessidade de uma maior interação entre Universidade e empresas para ajuste de necessidades mútuas, onde a metodologia utilizada 
pela Universidade reforce, junto aos alunos, a oportunidade de reflexões que proporcionem o desenvolvimento de competências de forma mais ampla.

Por outro lado, 33,3\% disseram que as competências adquiridas pelos alunos durante o curso, ocorre somente em parte. Assim, a interação entre UEMA e o mercado parece ser quase inexistente. Um total de 50\% deles entende que essa congruência contribui para uma parceria mútua entre empresa-escola e enriquece o currículo.

$\mathrm{Na}$ demanda por administradores, os gestores, na academia, ao apontarem as competências desejadas, centralizaram seus depoimentos nos fatores capacidade para aprender, criatividade e iniciativa. A maioria desses gestores $(66,7 \%)$ enfatizaram que não há diálogo entre o Curso de Administração da UEMA e as empresas de São Luís-MA; uma pequena parte $(16,7 \%)$ pontuou que o diálogo é bom, mas insuficiente. Assim, predomina o entendimento de que a comunicação e o relacionamento deixam muito a desejar.

Voltando a atenção aos gestores de RH da empresa VALE, verificou-se que eles possuem entendimento de competência com ênfase nos elementos: conhecimentos, habilidades e atitudes, os quais são enfocados, também, por alguns teóricos estudados.

A realização das entrevistas foi de grande importância, uma vez que com elas, pôde-se ratificar o posicionamento e compreensão registrados nos questionários respondidos pelos sujeitos desta pesquisa.

O conhecimento, na condição de base da formação acadêmica, é percebido como fundamental por alunos e gestores da UEMA, e congruente com as expectativas dos gestores de RH da VALE. É importante atentar, porém, para o fato de a empresa destacar a capacidade analítica na seleção de candidatos, pois, neste ponto, a insatisfação relatada pelos alunos quanto aos métodos de ensino dos professores, pode estar relacionada, merecendo melhor conhecimento dessa realidade, podendo motivar uma futura pesquisa institucional, a qual poderia ser promovida pelos gestores, com a colaboração de professores, alunos e, talvez, exalunos, também, para iluminar a questão.

A expectativa da empresa VALE sobre o conhecimento indica, além da competência técnico-científica, a competência para reflexão, o que é inerente a qualquer análise confiável. Assim, a preocupação dos gestores quanto aos alunos 'aprenderem a aprender', se soma o aprender a pensar.

Neste ponto, vale refletir com Zerbini e Plati Abbad (2012) ao recorrerem a Zerbini e Abbad (2008) alertam para a tendência dos alunos em cursos presenciais a buscarem a 
colaboração de outras pessoas, favorecida pela da interação face à face aluno-aluno, alunoprofessor. Quando essa interação é estimulada como integrante da metodologia de ensinoaprendizagem, na academia, pode fortalecer a preparação para o trabalho, também, pois além de poder estimular a atitude de equipe, pode contribuir para o desenvolvimento da competência analítica - a qual a empresa em estudo reconhece em seus critérios de seleção de pessoas - porque a interação tende a levantar posições diferentes, exigindo competência de análise dos envolvidos na busca por soluções a questões que se lhes apresente.

Na perspectiva da aprendizagem Organizacional, incluindo nesta a participação efetiva dos empregados, Senge (2001), propõe "tecnologias componentes", que embora desenvolvidas separadamente são interdependentes. São elas:

a) Pensamento sistêmico: refere-se a uma visão do todo organizacional. Embora nossa observação esteja vinculada a eventos isolados em uma determinada situação, a compreensão sistêmica só dera efetivada, quando adquirimos a capacidade de enxergar sua influência sobre o todo.

b) Domínio pessoal: diz respeito a capacidade do indivíduo estar continuamente aprofundando sua visão pessoal, concentrando suas energias, desenvolvendo paciência e enxergando a realidade dos fatos com objetividade.

c) Modelos mentais: relaciona-se a capacidade de um processo introspectivo contínuo, revendo nossas imagens internas e permitindo a revisão de comportamentos e atitudes, assim como a visão de mundo que congelamos ao longo da vida, não permitindo novas aprendizagens a partir das experiências e da visão dos outros.

d) Construção de uma visão compartilhada: Essa prática envolve as habilidades de descobrir um futuro compartilhado, estimulando um compromisso genuíno e o envolvimento, dando lugar a uma mera aceitação. Isso requer participação e comprometimento em conhecer a organização, seus objetivos, sua visão e sua missão.

e) Aprendizagem em equipe: Esta aprendizagem inicia-se a partir do momento em que as pessoas libertam-se dos seus preconceitos e abrem a possibilidade de olhar um determinado evento de forma diferente e possibilitar o pensamento conjunto. 
O interesse da VALE pela competência para resultados sustentáveis, da forma e no contexto em que foi apresentada pelos entrevistados, possibilita a interpretação de que esteja diretamente relacionada a conhecimento bem embasado e a atitudes responsáveis no trabalho.

Os destaques citados pelos entrevistados da VALE para habilidades relacionais, surge como um alerta e sugestão para o cotidiano dos gestores da Universidade, no sentido de observar-se até que ponto é um espaço que facilita o exercício relacional saudável entre todos os âmbitos que a instituem, quando questões emocionais poderão estar envolvidas.

Os resultados da pesquisa de campo levam a constatar que as competências exigidas para o administrador e contidas no Projeto Pedagógico do Curso são muito pouco conhecidas dos entrevistados, incluindo-se alunos e gestores da VALE e UEMA, haja vista a falta de alinhamento entre esses segmentos.

Além dos alunos, sujeitos da pesquisa, manifestarem insatisfação com a metodologia de ensino utilizada no Curso de Administração, tornou-se notório, também, que não há multidisplinaridade nas práticas, tendo em vista a falta de integração entre os diversos conteúdos envolvidos no processo ensino-aprendizagem, bem como a congruência entre o pensar e o agir dos atores envolvidos no processo de ensino-aprendizagem.

\section{CONSIDERAÇÕES FINAIS}

Apesar de várias questões resultantes deste estudo já haverem esboçado algumas conclusões, face à realidade constatada na pesquisa de campo, cabem ainda algumas reflexões em termos de considerações finais a partir do que já foi exposto.

É possível concluir que o entendimento sobre competência, segundo os sujeitos da pesquisa, coincide com a concepção de alguns autores apresentados no referencial teórico e oferecidos aos sujeitos para reflexão e respostas solicitadas. Contudo, houve significativas convergências da parte das três categorias de sujeitos - alunos, gestores da UEMA, gestores da VALE - em torno da definição de competência segundo Queiroz (2008), cujo conteúdo está amplamente relacionado às percepções expressas pelos próprios sujeitos sobre o que seria competência.

Essa constatação possibilitou concluir que o fato de o referencial teórico, em torno de competências, ter sido diversificado e oferecido dessa forma, à reflexão dos diferentes sujeitos, não dificultou as escolhas, pelo contrário, estimulou uma certa sintonia entre eles, o que traz expectativas de que a busca por um relacionamento mais próximo UEMA/ Empresa, 
conforme esperado pelos alunos, venha a ser bem sucedida. Sobre esse aspecto, conclui-se pela congruência entre a percepção de alunos e gestores da UEMA, tanto no que tange ao entendimento individual sobre o conceito de competência quanto em relação às diversas definições de competência apresentadas a ambas as categorias de sujeitos. Logo, os pressupostos se confirmam, em boa parte.

Os depoimentos dos gestores que enfatizando a fragilidade do diálogo entre a Universidade em foco e o empresariado pode ser um indicativo para questões relacionais mais amplas que poderiam ser investigadas em futuros estudos, mormente pelo fato de os alunos se utilizarem de termos como "falta de compartilhamento", reforçados pela posição da grande maioria dos gestores, sujeitos da pesquisa, quando consideram não haver diálogo entre o Curso de Administração da UEMA e as empresas locais, além de algumas poucas, mas contundentes vozes, considerando que os contatos "são insuficientes".

Neste ponto, é válido lembrar que os alunos, em sua maioria, consideram a questão profissional como de sua própria iniciativa, o que sugere uma revisão pelos gestores da UEMA em todo o processo de estágios, desde um diálogo mais frequente e profícuo com as organizações de trabalho que oferecem vagas, até a preparação e o apoio aos estudantes, visando a que essas oportunidades realmente contribuam para implementar a formação de administradores que a Universidade oferece.

A insatisfação dos alunos, quanto ao estágio, leva a concluir sobre a expectativa dos discentes em termos de um acompanhamento da UEMA, nessa etapa do Curso. Na verdade, a ênfase da crítica dos alunos não recai sobre a empresa, pois eles parecem perceber a estreita relação entre o estágio e o estudo, esperando da instituição de ensino o devido apoio para a integração teoria e prática, o que deixa clara a importância dos métodos de ensino e subjacente a expectativa positiva nas condições da UEMA para coordenar o processo interativo.

Essa reação possibilita inferir que há confiança no que a Universidade tem feito através de seu Curso de Administração, em termos teóricos, para o embasamento do conhecimento dos administradores, devendo implementar a preparação para enfrentar o mercado de trabalho, durante o requisito de estágio profissional. Tais reações dos alunos também merecem atenção das empresas, pois, percebe-se que a expectativa é por um estágio visto não apenas como uma mão-de-obra de baixo custo, ou até mesmo compreendido como algo fictício, mera formalidade legal, mas, sim, uma real oportunidade de iniciação à 
profissionalização e oportunidade de autoconhecimento, percepção de potenciais, talentos e contato direto com novos contextos e culturas.

Dessa forma, ao completar o ciclo acadêmico, o aluno estaria familiarizado com o trabalho em administração para benefício não somente próprio e o prestígio da academia, mas para atender às necessidades do empregador e, também, com a formação esperada para seu futuro quadro de pessoal.

Diante desse cenário, necessária se faz, a implementação de algumas medidas no sentido de aproximar a UEMA das empresas de São Luís-Maranhão, pois, assim, se ampliará a congruência buscada neste estudo, entre as competências adquiridas pelos alunos do Curso de Administração da UEMA e as requeridas pelos gestores de empresas. Porém, fica descartado qualquer indício de confusão entre aproximação empresa-escola, no sentido de redução da Universidade à mera capacitação de mão de obra, porque, essa atitude não apareceu em nenhum dos grupos de sujeitos definidos, quer fossem alunos, gestores na UEMA ou gestores na organização empresarial.

Convém ressaltar, que o conceito de competências encontra-se em construção. Portanto, ainda há muito o que pesquisar sobre esse assunto. Contudo, as experiências analisadas mostram indícios de benefícios que uma gestão de pessoas, calcada em competências, pode proporcionar às pessoas e à própria organização.

O envolvimento das pessoas para identificar competências favorece o surgimento de condições que viabilizam o empenho e o compartilhamento na compreensão do seu significado e da disposição para desenvolvê-las.

Em vista do exposto, necessária se faz a realização de estudos futuros, a fim de se aprofundar a análise dos impactos do processo de identificação e desenvolvimento de competências a partir de novos indicadores.

\section{REFERÊNCIAS}

BILLIS, D.; ROWBOTTOM, R. Organizational design: the work level approach. Camdridge: Gower, 1987.

DAVIS, J. H. The future of salary surveys when jobs disappear. Compensation \& Benefits Review, v. 29, n. 1, p.18-26, Jan. 1997.

DURAN,T.L'alchimie de la compétence. Revue Française de Gestion. Paris, 127, p.88102,Janvier-Février, 2000. 
DUTRA, J. S. D. et al. Gestão por competências: um modelo avançado para o gerenciamento de pessoas. São Paulo: Gente, 2001.

FLEURY, M. T.; FISCHER, R. M. Relações de trabalho e políticas de gestão: uma história das questões atuais. Revista de Administração da USP, v. 27, n. 4, out./dez. 1992.

FREITAS ,I,A.;BRANDÃO, H. P. trilhas de aprendizagem como estratégia de TD\&E. In:Treinamento, Desenvolvimento e Educação em Organizações de Trabalho: fundamentos para a gestão de pessoas. Pôrto Alegre: Artmed, 2006.

JAQUES,E. Requisite organization: a total system for effective managerial organization and managerial leadership for the $21^{\mathrm{a}}$ Century. Arlington: Cason Hall, 1988.

KIRSCHBAUM, C.; IWAI; T. Teoria dos jogos e microssociologia: avenidas de colaboração. Revista de Administração Contemporânea. vol.15 no.1 Curitiba jan./fev. 2011. http://dx.doi.org/10.1590/S1415-5552011000100009

MINAYO, M. C. de S. (Org.). Pesquisa social: teoria, método e criatividade. $2^{\mathrm{a}}$ ed. Petrópolis: Vozes, 1994.

QUEIROZ, C. As competências das pessoas. São Paulo: DVS, 2008.

SENGE, PETER M. A quinta disciplina: arte e prática da Organização que aprende. São Paulo: Best Seller, 2001.

TAYLOR, F. W. Princípios de administração científica. São Paulo: Atlas, 1982.

VIEIRA, M. M. F. Por uma boa pesquisa (qualitativa) em administração. In: VIEIRA, M. M. F.; ZOUAIN, D. M (Org). Pesquisa qualitativa em administração. Rio de Janeiro: Fundação Getúlio Vargas, 2004.

ZARIFIAN, P. Objetivo competência: por uma nova lógica. São Paulo: Atlas, 2001.

ZERBINI, T. ABBAD, G. Estratégias de aprendizagem em cursos a distância: validação de uma escala. Psico-USF, 13 (2), 177-178227, 2008.

ZERBINI, T., RONALDO, P. Medidas de insumo: perfil cognitivo-comportamental da clientela de ações TD\&E. In: Medidas de Avaliação em Treinamento, Desenvolvimento e Educação: ferramentas para gestão de pessoas. (Org.) Abbad, Gardênia da Silva et all. Pôrto Alegre: Artmed, 2012. 